\section{Nunca fomos Flexnerianos: Anísio Teixeira e a educação superior em saúde no Brasil}

\author{
We have never been Flexnerians: Anísio Teixeira \\ and higher education in health in Brazil
}

\author{
Nunca fuimos Flexnerianos: Anísio Teixeira y la \\ educación superior en salud en Brasil
}

\author{
${ }^{1}$ Instituto de Saúde Coletiva, \\ Universidade Federal da \\ Bahia, Salvador, Brasil. \\ Correspondência \\ N. Almeida Filho \\ Instituto de Saúde Coletiva, \\ Universidade Federal da \\ Bahia. \\ Rua Padre Feijó 29, 4o andar \\ Salvador, BA 40210-070, \\ Brasil. \\ naomaralmeida@gmail.com
}

\begin{abstract}
The aim of the current article is to explore central features of Anísio Teixeira's "thought-action" approach in order to help overcome the current crisis in health personnel training. First, the article summarizes Teixeira's life and work, assessing his institutional legacy and its impact on the historical scenario in Brazil's educational system. Second, it discusses his model for a People's University, promoted and implemented twice in Brazil's recent history, but crushed by harsh political repression. Third, the article assesses the potential contribution of Teixeira's work to the current political and pedagogical debates on professional and academic training in health, focusing on similarities with Flexnerian models for university reform. Finally, it raises the hypothesis that the conceptual and pragmatic convergence between Abraham Flexner and Anísio Teixeira allows understanding the absence or invisibility of Teixeira's thinking in the academic literature on Health Education, in the institutional discourse, or in human resources training practices in Brazil.
\end{abstract}

Health Education; Universities
Naomar Almeida Filho ${ }^{1}$

\section{Resumo}

O objetivo do presente artigo é examinar elementos centrais do pensamento-ação de Anísio Teixeira, visando produzir subsídios para superação da atual crise de formação de pessoas em saúde. Primeiro, apresenta-se resumo de vida e obra de Anísio, avaliando seu legado institucional e impacto no cenário histórico da educação brasileira. Segundo, discute-se o modelo anisiano de Universidade Popular, promovido e implantado em duas oportunidades na história brasileira recente, porém reprimido politicamente com dureza. Terceiro, avalia-se a contribuição potencial da obra anisiana para os debates políticopedagógicos atuais sobre formação profissional e acadêmica em saúde, focalizando similaridades com modelos flexnerianos de renovação da universidade. Por último, propõe-se a hipótese de que a convergência conceitual e pragmática entre Flexner e Anísio permite compreender a constatada ausência ou invisibilidade do pensamento anisiano na literatura acadêmica sobre Educação em Saúde, no discurso institucional e nas práticas de formação de trabalhadores em saúde no Brasil.

Educação em Saúde; Universidades 
A correlação de forças que promoveu a redemocratização do Brasil após o regime militar criou condições para incluir a saúde entre os direitos da cidadania e para ampliar cobertura e participação social na gestão pública do setor saúde, ao conceber, estabelecer e consolidar o Sistema Único de Saúde (SUS) 1. Entretanto, avanços políticos no campo da saúde não têm sido suficientes para reconfigurar modelos de formação profissional seculares ainda vigentes na realidade brasileira ${ }^{2}$. Corporações, segmentos sociais e instituições tradicionais, hegemônicos, posicionam-se contra a renovação ideológica e pedagógica da universidade, rejeitando modelos contemporâneos de educação superior, principalmente no campo da saúde. Nessa conjuntura, há evidências de uma profunda crise no sistema de formação universitária em saúde no Brasil 3,4,5.

Um dos principais paladinos da renovação da universidade brasileira, em todos os planos e vertentes, foi o educador Anísio Teixeira. Líder institucional obstinado e criativo, sintonizado com os debates epistemológicos mais avançados do seu tempo, antecipou a emergência dos paradigmas da interdisciplinaridade e da complexidade no panorama das ciências contemporâneas, precursor de modelos ativos de ensino-aprendizagem e defensor de uma perspectiva humanístico-artística na educação 6,7,8. No plano político, Anísio via a educação como promotora da democracia e a instituição universitária como indutora de desenvolvimento cultural, artístico, econômico e tecnológico do ser humano ${ }^{8}$. A atualização do pensamento-ação de Anísio Teixeira sem dúvida poderá contribuir para a superação da crise atual da universidade brasileira, em particular da formação em saúde.

Infelizmente, até onde pudemos perscrutar, inexistem estudos e reflexões sobre o potencial da contribuição anisiana para superar a crise estrutural da educação universitária em saúde em nosso país. Busca bibliográfica nas bases MEDLINE, SciELO, LILACS e BVS, complementada por verificação no Goggle e Google Scholar, usando os indexadores < anisio teixeira + saúde $><$ anisio teixeira + saúde + educação $>$, sem filtros temporais ou geográficos, indica escassa ocorrência de registros. Poucos estudos 9,10,11,12,13,14 fazem referência ao nome, mas em todos os casos somente porque o Instituto Nacional de Estudos e Pesquisas Educacionais Anísio Teixeira (INEP) foi a fonte dos dados coletados nos respectivos estudos. A constatação mais eloquente desta lacuna encontra-se numa nota editorial ${ }^{9}$ sobre possibilidades de transformação da educação em saúde pela interlocução entre academia e governo, justamente um dos temas mais centrais e recorrentes na obra anisiana, que também menciona o nome Anísio Teixeira apenas ao indicar o INEP como órgão oficial de avaliação de dados na área de Educação.

De fato, no campo da saúde, não encontramos qualquer publicação acadêmica ou institucional sobre a potencial aplicabilidade do pensamento filosófico-político e da contribuição pedagógica e organizacional de Anísio Teixeira. Esta omissão foi registrada de modo agudo por Temporão 5 , ao analisar recentemente a pobreza teórica do debate sobre a educação em saúde no Brasil, num breve comentário intitulado Educação na Saúde e Saúde na Educação: "Nesse contexto, como não ficar com um sentimento nostálgico pelas ausências de Anísio Teixeira e de Darcy Ribeiro?".

O objetivo do presente artigo é contribuir para a compreensão e, eventualmente, para o preenchimento dessa lacuna, ao apresentar à comunidade acadêmica e de serviços do campo da saúde elementos centrais do pensamento-ação de Anísio Teixeira, visando produzir subsídios para superação da atual crise de formação de trabalhadores em saúde. Em primeiro lugar, apresentamos um resumo de vida e obra de Anísio, seu legado institucional e impacto no cenário histórico da educação brasileira. Em segundo lugar, discutimos o modelo anisiano de Universidade Popular, promovido e implantado em duas oportunidades na história brasileira recente, porém reprimido politicamente com dureza. Em terceiro lugar, avaliamos a contribuição potencial da obra anisiana para os debates político-pedagógicos atuais sobre formação profissional e acadêmica em saúde, focalizando similaridades com modelos flexnerianos de renovação da universidade. Por último, propomos a hipótese de que a convergência conceitual e pragmática entre Anísio e Flexner permite compreender a constatada ausência ou invisibilidade do pensamento anisiano na literatura acadêmica sobre Educação em Saúde, no discurso institucional e nas práticas de formação de trabalhadores em saúde no Brasil.

\section{Anísio Teixeira: resumo biográfico}

Além de competente gestor acadêmico e importante líder institucional, Anísio Spínola Teixeira (1900-1971) produziu rica e profícua obra filosófica, política, sociológica e pedagógica $15,16,17,18,19,20,21,22,23,24$.

Nascido em Caetité, interior da Bahia, tem formação religiosa no Colégio Antônio Vieira, da ordem Jesuíta, em Salvador. Recém-graduado em Direito e muito jovem, assume o cargo que hoje equivaleria a Secretário Estadual de Educação. Revela-se gestor público competen- 
te e, em menos de três anos, realiza verdadeira revolução, ao garantir acesso pleno ao ensino básico em Salvador 8. O sucesso de Anísio nessa primeira atuação como gestor institucional é tão notável que, ao organizar, no Rio de Janeiro um governo democrático em plena Ditadura Vargas, Pedro Ernesto convida-o para o cargo de Diretor de Instrução. Rapidamente, Anísio analisa o contexto e propõe uma reorganização para o conjunto de problemas enfrentados pelo que hoje se chama ensino básico. Estrutura o ensino primário e secundário numa rede pública regionalizada com acesso pleno, independentemente de classe social. Para completar a oferta de educação numa rede pública articulada em todos os níveis de formação, esboça o projeto da Universidade do Distrito Federal, envolvendo os maiores artistas e intelectuais do Brasil naquele momento: Villa-Lobos, Sérgio Buarque de Holanda, Cândido Portinari, Josué de Castro, Gilberto Freyre, Afrânio Peixoto, Oscar Niemeyer, Mário de Andrade, entre outros 24. A Ditadura Vargas e a Igreja Católica veem sua aliança conservadora ameaçada pelas ideias de Anísio. Os jesuítas, dominando o cenário brasileiro da educação superior, fazem oposição cerrada ao jovem educador saído de suas próprias bases. Alceu Amoroso Lima, líder intelectual da direita católica, inicia forte campanha de difamação, descrevendo Anísio como infiel, demoníaco e comunista. Denunciado como envolvido na Intentona Comunista de 1935 , perseguido pelo Departamento de Ordem Política e Social (DOPS), Anísio se refugia em Caetité, de onde assiste Gustavo Capanema, Ministro da Educação de Vargas, nomear justamente Amoroso Lima como Reitor da Universidade do Distrito Federal, com a finalidade explícita de desmontála como experimento institucional 8,25.

Após uma década de auto-exílio, em 1945, Anísio é convidado a organizar o Departamento de Educação Superior da Organização das Nações Unidas para a Educação, a Ciência e a Cultura (UNESCO) em Nova York, Estados Unidos. Depois da queda de Vargas, aceita o convite de Octávio Mangabeira para dirigir a Secretaria de Educação e Saúde Pública da Bahia. Esse é o momento mais frutífero da trajetória de Anísio, pois representa ocasião de colocar em prática várias de suas ideias, com financiamento suficiente e forte apoio político. Data dessa época a criação da Escola Parque de Salvador e da pioneira Fundação Estadual de Apoio à Pesquisa. Pode-se dizer, portanto, que Anísio Teixeira constitui um dos esteios intelectuais da fase áurea do desenvolvimentismo nacional, ocupando-se, por mais de uma década, do mais importante requisito para o desenvolvimento que é a Educação ${ }^{8}$.
No final da década de 1950, Anísio passa a trabalhar no Ministério da Educação e Cultura, onde funda a Coordenação para o Aperfeiçoamento de Pessoal de Nível Superior (Capes). Nesse momento, como parte do projeto desenvolvimentista de Juscelino Kubitscheck, planeja-se Brasília como a cidade vanguarda do mundo, merecedora de um modelo de universidade também o mais avançado da época. Demanda-se à UNESCO um consultor capaz de conceber e ajudar a criar essa universidade. Anísio já realizava no Ministério da Educação e Cultura um conjunto de atividades de grande fôlego, baseado no INEP, do qual era também diretor-geral. Convocado diretamente pelo Presidente Kubitschek, Anísio convida o jovem antropólogo e escritor Darcy Ribeiro (19221997), então seu discípulo e colaborador, que aproveita a oportunidade para se firmar como liderança de rápida ascensão naquele momento político. Com a ajuda dos principais intelectuais brasileiros, entre artistas e cientistas da época, concebe um projeto que recupera o ideário da Universidade do Distrito Federal, vanguarda na década de 1930, e o atualiza, incluindo novas ideias que desenvolvera entre 1954 e 1960, publicadas na Revista do INEP e em outros periódicos 15,16,17,18,19.

O Projeto de Lei de criação da Universidade de Brasília tem Anísio Teixeira como Presidente da Comissão de Elaboração e Darcy Ribeiro como seu Relator 26. Juscelino confirma seu grande entusiasmo pela proposta, incluindo-a na mensagem presidencial ao Congresso Nacional que, em 21 de abril de 1960, marca a inauguração da nova capital. Durante o curto período do governo Jânio Quadros (de janeiro a agosto de 1961), o projeto fica engavetado. Sua aprovação ocorre no dia da renúncia de Jânio, em circunstâncias inusitadas: Darcy consegue colocá-lo no pacote de projetos que iriam à votação em bloco, com o Congresso mergulhado no caos; quando termina a sessão parlamentar, estava criada a Universidade de Brasília (UnB), sem que os deputados soubessem que a tinham aprovado 26.

Darcy Ribeiro é nomeado Reitor e Anísio, vice. Contudo, como Darcy assumira a Chefia da Casa Civil do Governo Goulart, Anísio foi, de fato, o primeiro reitor da UnB. A UnB nasce com desenho e uma estrutura inovadores de instituição universitária organizada em institutos de ciências básicas e centros de formação, visando superar o modelo bonapartista de faculdades e grandes escolas 26,27 . Na prática, a proposta implicava ciclo de dois anos de formação geral, completado por mais um ano de bacharelado em grandes áreas do conhecimento. Somente após o bacharelado geral é que se obtinha acesso à graduação profissional específica. Esse modelo remete ao 
college norte-americano, vivenciado por Anísio ao realizar sua formação como educador nos Estados Unidos, como veremos adiante 8 .

O modelo de ciclos concebido por Anísio chega a ser implantado na UnB, porém o projeto sofre forte reação política contrária. Essa resistência dirige-se contra todos os projetos de reforma de base do governo João Goulart, inclusive modelos avançados de educação (incluindo a pedagogia de Paulo Freire). Não obstante, sob a liderança de Anísio e o apoio político de Darcy, a UnB se implanta tendo a pesquisa e a ação cultural como referências institucionais. Cientistas, artistas, professores e intelectuais progressistas, brasileiros e estrangeiros, acorrem a Brasília, uma nova "meca acadêmica". Aí vem o golpe militar de 1964.

O principal movimento de tropas no Distrito Federal depois do golpe é a ocupação da UnB, narrada em detalhes por Roberto Salmeron num livro marcante, A Universidade Interrompida 27. Anísio Teixeira é exonerado, compulsoriamente aposentado, sem direito a pensão ou outra prerrogativa. Estudantes são levados sob a mira de armas pesadas e detidos no Ginásio de Esportes. Professores fichados e alguns demitidos. O conjunto de dirigentes renuncia; porém, aconselhados por Anísio, resolvem permanecer para resistir. A universidade continua funcionando por mais algum tempo, pois o reitor nomeado, o médico Zeferino Vaz, acolhe o modelo curricular inicialmente proposto e concorda com as inovações acadêmicas, até ser demitido com alguns docentes pelos militares, em outubro de 1965. Nesse momento, 263 professores se demitem em protesto e o projeto da UnB encerra-se 27 . Uma sucessão de reitores interventores, com destaque para o militar José Carlos Azevedo, conduz por duas décadas o desmonte da proposta anisiana, que culmina, já recentemente, com um processo espontâneo de refragmentação dos cursos e instauração de faculdades nos moldes convencionais.

Depois de inocentado numa CPI no Congresso Nacional e de responder a um Inquérito Policial Militar, Anísio exila-se no Chile e nos Estados Unidos, retornando ao Brasil a tempo de participar dos movimentos em prol da reforma universitária ${ }^{8}$. Falece em 1971, no Rio de Janeiro, em circunstâncias misteriosas que estão sendo investigadas pela Comissão Nacional da Verdade como possível resultado de sequestro, tortura e assassinato por órgãos de repressão do regime militar 28 .

\section{O conceito anisiano de educação superior}

Anísio Teixeira foi um ativista político (mas sempre apartidário) que defendia a educação superior como indutora de desenvolvimento artístico, econômico, social, cultural, em suma, humano. A partir da perspectiva filosófica do pragmatismo, formulou conceitos fundamentais sobre o que designava como Educação Democrática 22. Ao considerar a educação como vetor potencial da emancipação humana, defendeu o caráter polí tico dos processos pedagógicos para a integração entre pensamento e ação, num projeto libertário inspirado no pensamento deweyano. A perspectiva anisiana prevê uma revolução democrática, pacífica e sustentável viabilizada pela universalização da educação nos níveis iniciais - como condição de emancipação política e equidade social - e pela ampla oportunidade de acesso à educação superior em instituições universitárias de fato abertas ao povo 17,22,23,24.

Num discurso de formatura, intitulado Mestres de Amanhã 16, Anísio sintetiza sua aguda visão premonitória, antecipando um futuro que hoje se faz presente.

"Estamos entrando em uma fase nova da civilização chamada industrial, com a explosão contemporânea dos conhecimentos, com o desenvolvimento da tecnologia e com a extrema complexidade conseqüente da sociedade moderna. [...] Se a isto juntarmos a explosão de conhecimentos e as mudanças que os novos conhecimentos, com suas conseqüências tecnológicas, estão a trazer, podemos imaginar até que ponto as forças do costume, dos hábitos e das velhas crenças e preconceitos vão ser destruídas e quanto vai o homem depender de sua cultura formal e consciente, de seu conhecimento intelectual, simbólico e indireto, para se conduzir dentro da nova e desmesurada amplitude de sua vida pessoal. [...] A educação para este período de nossa civilização ainda está para ser concebida e planejada e, depois disto, para executá-la, será preciso verdadeiramente um novo mestre, dotado de grau de cultura e de treino que apenas começamos a imaginar" 16 (p. 11).

Visando à educação emancipadora "para todos e não apenas para alguns", reafirma sua posição política de educador comprometido com a igualdade, viabilizada na prática pelo uso intensivo das então incipientes tecnologias educacionais. Ao fazê-lo, antecipa o contexto atual de valorização das metodologias ativas de aprendizagem mediadas por tecnologias de informação e comunicação.

Para Anísio Teixeira, com o esgotamento da universidade clássica, houve lugar para o surgimento da universidade moderna 21,23. Em tal modelo, originalmente germânico e depois an- 
glo-saxão, além do ensino, a pesquisa se torna atividade institucional permanente. Segundo a original concepção anisiana, a universidade é a única instituição social capaz de promover a recriação contínua da cultura 17,18,19,20,21,22,23. Esta atribuição envolve uma tomada de partido, ao integrar a universidade à vida da sociedade e ao exercitar um extenso e intenso olhar crítico sobre o mundo que a cerca $6,7,8$. Isso inclui, necessariamente, a capacidade de olhar sobre si mesma, sem qualquer espécie de paternalismo, como instituição que, ao dosar delicadamente necessidade com contingência, permite corrigir, a cada tempo, seu próprio rumo histórico. Neste aspecto, ao examinar os dilemas cruciais da Universidade ao longo da sua história, antecipa o que Boaventura de Sousa Santos 29 chamaria de crise de identidade da instituição universitária: formar profissionais ou promover a ciência e a cultura? Educar cidadãos ou credenciar profissionais? Servir às elites ou servir ao povo?

Em distintos momentos de sua vida, Anísio Teixeira enfrenta a questão de como popularizar sem vulgarizar, como pagar a dívida social da educação brasileira sem destruir o sonho de uma universidade competente e criativa. Uma resposta teórica, política e efetivamente prática a essa série de aparentes dilemas conforma a criação, organização e consolidação de uma Universidade Popular, em três planos complementares.

Em primeiro lugar, no plano pedagógico, a solução do dilema da massificação com qualidade e integralidade encontra-se no uso intensivo das tecnologias educacionais mais atualizadas. Com clareza, numa perspectiva antecipatória e visionária, já na década de 1960 explicita sua convicção da importância das novas tecnologias de informação e comunicação 16 (p. 19): “os novos recursos tecnológicos e os meios audiovisuais irão transformar o mestre no estimulador e assessor do estudante, cuja atividade de aprendizagem deve guiar, orientando-o em meio às dificuldades da aquisição das estruturas e modos de pensar fundamentais da cultura contemporânea de base científica em seus aspectos físicos e humanos".

Porém a tecnologia e a ciência seriam " $l i$ mitadas como formadoras da cultura que, nesse sentido, precisaria recorrer a outros saberes como a filosofia, concebida como conjunto de valores e aspirações, as ciências biológicas, psicológicas e sociais, todas as demais ciências como conteúdo do ensino, enfim, a cultura, a civilização e o pensamento humano em seus métodos e resultados" 16 (p. 18).

Dessa maneira, Anísio demonstra enorme confiança na tecnociência como índice de modernidade e qualidade das práticas educacio- nais, além de fonte de soluções inovadoras para os dilemas relacionados aos projetos de popularização da educação universitária.

Em segundo lugar, num plano antropológico, a proposta de Universidade Popular tem como fundamento histórico a dura crítica anisiana ao papel da educação como promotora de uma dupla alienação cultural, essencial para a consolidação da estrutura política desigual da sociedade brasileira pós-colonial. Em suas palavras 23 (pp. 93-4): “[No Brasil do Império e da República] tínhamos duas alienações no ensino superior. A primeira grande alienação é que o ensino, voltado para o passado e sôbre o passado, nos levava ao desdém pelo presente. A segunda alienação é que tôda a cultura transmitida era cultura européia. Recebíamos ou a cultura do passado, ou a cultura européia. E nisto tudo o Brasil era o esquecido. A classe culta brasileira refletia mais a Europa e o passado do que o próprio Brasil: estávamos muito mais inseridos na verdadeira cultura ocidental e até na antiga - latina e grega - do que em nossa própria cultura. [...] todo o passado brasileiro era conservado em cultura estrangeira. A alienação não é uma figura de retórica; mas, uma realidade. Educaram-nos em uma cultura diversa da cultura local".

Em terceiro lugar, no plano organizativo institucional, a perspectiva anisiana de uma educação integral tem como principal elemento uma estreita articulação do ensino superior com o ensino secundário, com oferta ampla e aberta a todos os segmentos da população. Tal articulação se realizaria mediante bacharelados de prégraduação (mas já no nível universitário de formação geral), realizados numa rede de colégios universitários. Anísio Teixeira concebe a ideia do “colégio universitário" desde cedo em sua carreira de líder intelectual da educação brasileira, ao retornar da Universidade de Columbia. Em vários escritos, Anísio detalha a estrutura curricular dos Colégios Universitários: cursos de cultura geral; preparatórios para avançar na formação universitária; propedêuticos para ingresso nas escolas profissionais; cursos vocacionais para carreiras curtas, "ampliando a sua capacidade de admissão para acolher todos os que estiverem em condições de receber alguma espécie de ensino superior" 21 (p. 189).

A primeira oportunidade de colocar em prática tais princípios e propostas é a criação da Universidade do Distrito Federal em 1934/1935 25, concebida em articulação com um centro de formação de professores e uma faculdade central de ciências e letras, entrada única para estudantes que completassem o ensino secundário na rede pública que ele havia implantado. Como vimos, essa iniciativa foi abortada em fase inicial de im- 
plantação e seu modelo duramente reprimido pela Ditadura do Estado Novo.

O conceito anisiano de uma universidade popular integrada à rede de educação pública teria nova oportunidade de materialização no final da década de 1940, após seu retorno de Nova York. Este momento foi captado no depoimento de Carybé, pintor argentino radicado na Bahia desde 195630 (pp. 15-6): "Rubem Braga, um dia, fez uma carta para Anísio Teixeira, secretário de Educação e Cultura, e me disse: 'vai ver esse homem que ele vai lhe dar um emprego na Bahia'. Olhei a carta e fiquei morrendo de vergonha de tanto elogio que ele fazia. Aí vim para a Bahia. Entreguei a Anísio. Ele leu e disse: 'vamos ver, estou fazendo umas escolas, uma espécie de universidade popular e gostaria de fazer um painel e até tenho um recorte de uma ilustração sobre a Bahia. Mandou a secretária buscar. Não tinha mais assunto quando a secretária voltou, era um almanaque que eu tinha feito. Aí pronto. Ele me disse: 'você vem para o ano e vamos arranjar".

A referência a "uma espécie de universidade popular" remete ao projeto da escola integral, concretizada parcialmente na famosa Escola Parque de Salvador que, de fato, abriga até hoje um mural alegórico sobre estudantes trabalhadores, uma das obras-primas de Carybé.

A principal contribuição de Anísio ao Projeto de Lei da primeira LDB, bastante discutido porém não aprovado pelo Congresso Nacional no período pós-Vargas, foi justamente esse modelo de educação integrada, do primário ao ensino superior, detalhando uma educação universitária em regime de ciclos 20 . Na universidade reformada de Anísio, o primeiro ciclo compõe-se de dois níveis de formação: curso básico e curso propedêutico. Por sua clareza, precisão, pertinência e convergência, vale a pena reproduzir na íntegra a seguinte citação do livro Educação e Universidade 23 (pp. 154-5): "Cabe aqui, antes de prosseguir, examinar a designação de ensino básico que se vem introduzindo em nossa terminologia da reforma. [...] um ensino geral, introdutório ou propedêutico ao estudo superior no nível acadêmico ou no nível profissional, ou destinado a uma ampliação da cultura secundária, para os que não desejassem fazer carreira acadêmica ou profissional. [...] O curso de cultura geral é diferente de um curso propedêutico e este curso propedêutico se diversifica pelo ramo de que ele deseja ser propedêutico. O de cultura geral é uma iniciação, uma introdução a um ramo do saber, com o objetivo central de alargar a mente do educando, de lhe dar novas vistas da realidade e de aparelhá-lo com certas idéias necessárias para compreender o mundo do saber, a sua diversidade, $e$ ajudá-lo a pensar com maior riqueza de imagina- ção. Já o curso propedêutico pode alcançar alguns desses efeitos, mas não pode ser tão desinteressado e tem de levar em conta a aplicação do conhecimento examinado no campo para que deseja ser propedêutico. O curso geral em certos casos pode ser propedêtico ao curso de especialização acadêmica, mas somente como elemento para a escolha do campo a que se vai dedicar".

Na sua proposta de reforma universitária 21,23, Anísio já prevê cursos de formação geral, ao modo dos Bacharelados Interdisciplinares, como uma possibilidade de acesso universal à educação universitária. Além disso, indica 23 , sem hesitação, que as trajetórias de seleção para carreiras profissionais ou acadêmicas implicariam opções em um mesmo ciclo de formação com a "introdução da formação acadêmica ao lado $e$ independente da profissional" 23 (p. 155). O seguinte trecho sintetiza com clareza a proposta anisiana de universidade popular 23 (p. 156): “ $A$ reforma resolveria, assim, o problema da admissão à universidade, abrindo os seus portões para acolher a mocidade, que terminara o curso secundário e alimentava o propósito de continuar os estudos, para um curso introdutório, de nível superior, destinado a alargar-lhes a cultura geral recebida no nível secundário, dar-lhes uma cultura propedêutica para as carreiras acadêmicas ou profissionais ou para treiná-los em carreiras curtas de tipo técnico. Terminados esses cursos é que iria ele ser selecionado para os cursos regulares de graduação nas carreiras acadêmicas ou profissionais. Depois desta formação, nova seleção far-se-ia de imediato ou posteriormente, para a escola pós-graduada".

O projeto desta universidade renovada, uma instituição massificada e popular, como vimos, inspira-se em reflexões, conceitos e iniciativas de construção institucional, desenvolvidos e aplicados pioneiramente na Universidade do Distrito Federal e na Escola Parque. Vários elementos estruturais previstos na proposta da universidade popular reaparecem no projeto original (de fato, nunca totalmente implementado) da Universidade de Brasília 31 e em outros escritos anisianos sobre a instituição universitária 21,23: componentes curriculares gerais e específicos, incluindo o conceito de cursos-tronco; caráter majoritariamente optativo do currículo; articulação entre bacharelados curtos, carreiras profissionais de média duração e carreiras longas; natureza interdisciplinar (naturalmente sem a terminologia atual, que seria criada posteriormente) dos ciclos iniciais de formação; estrutura modular não-especializada e organização por níveis de formação; articulação do sistema de unidades centrais e escolas de pós-graduação ${ }^{21}$. 
Além de historicamente mais próximo da conjuntura atual, o projeto da UnB merece especial destaque na medida em que a principal discordância entre seus criadores situava-se na proposta defendida por Anísio de oferecer, no campus central, apenas cursos profissionalizantes e doutorados. Essa posição foi criticada por muitos como elitista e contraditória com os princípios da educação democrática e emancipadora que o próprio Anísio postulava 26. Entretanto, os críticos dessa visão omitem o fato de que, como elemento central do conceito anisiano de Universidade Popular, a concepção de uma rede de colégios universitários é chave para a necessária ampliação do acesso à educação superior aos grupos sociais historicamente excluídos. O potencial político de uma estrutura curricular descentralizada e capilarizada na comunidade, integrada ao regime de ciclos de formação, não passa despercebida aos agentes do conservadorismo, tanto que outras versões nacionais do college herdeiras do modelo UnB - UFMG em 196531 e Unicamp em 1967 32,33 - também foram reprimidas duramente pelo regime militar.

Enfim, a universidade que temos hoje, montada pelos militares e seus intelectuais orgânicos, resulta do que se chamou de Reforma Universitária de 1968 34,35,36. Fruto de um tratado internacional que o Brasil assinou com os Estados Unidos, patrocinadores do golpe militar, essa reforma representou uma aliança da burguesia com a oligarquia acadêmica, na medida em que se fez uma mudança conservadora no sistema nacional de educação. Assim, bem distante da concepção anisiana, conserva-se o regime bonapartista de formação de profissões em faculdades, onde os alunos entram diretamente na formação profissional, forçando os jovens a escolher precocemente a direção de sua vida. Essa entrada direta, através de um processo seletivo extremamente rigoroso, competitivo e socialmente injusto, objeto de intensa judicialização, principalmente no que se refere à universidade pública, fez com que o sistema universitário brasileiro cultivasse absurda rigidez e inflexibilidade, de modo que quem entra num curso profissional não pode mudar, não terá mobilidade, não pode fazer ajustes em suas decisões. Mantém-se uma estrutura de graduação arcaica e anacrônica, tal como eram a educação superior francesa e lusitana em 1890 e o modelo norte-americano antes da Reforma Flexner em 191034.

Após a redemocratização, diretamente influenciado pelas propostas de Anísio Teixeira, seu discípulo Darcy Ribeiro, então Senador, inclui na Relatoria do Projeto de Lei da LDB aprovada e promulgada em 1996, atualmente vigente, a adoção dos cursos sequenciais, em modalidades acadêmicas e profissionalizantes (nesse caso, chamada de Cursos Superiores Tecnológicos) 37 . Infelizmente, a viabilização dessa proposta nas décadas seguintes resulta numa situação ainda vigente de redes públicas de ensino superior distintas, desarticuladas e quase antagônicas, separando o ensino tecnológico da formação acadêmica, praticamente proibindo formas de articulação interinstitucional capazes de propiciar a desejada mobilidade entre os sistemas públicos de ensino superior.

\section{Anísio Teixeira, Abraham Flexner e a formação em saúde no Brasil}

Retomemos a questão central deste ensaio. Realmente, causa grande surpresa o fato de que o pensamento-ação do maior teórico da educação brasileira ter sido sistematicamente excluído do debate sobre formação profissional em saúde no país. Cabe-nos especular sobre motivos e explicações para essa eloquente ausência, pois a rica, profunda e diversificada contribuição de Anísio aos debates políticos e pedagógicos sobre os problemas da educação, em especial sobre a formação de profissionais e de docentes, seria certamente de grande valia na superação da atual crise da saúde no Brasil.

Seguramente não se trata de movimento reativo, que seria justificado caso existisse na obra anisiana menosprezo ou confronto em relação ao campo da saúde ou ao pensamento médico. Muito pelo contrário. Anísio demonstra grande respeito e admiração pela qualidade científica da formação médica realizada no Brasil na primeira metade do século XX. Em várias oportunidades, reconhece a importância histórica e intelectual dos cursos de Medicina nos primórdios da educação superior no Brasil e afirma que representam modelos de modernidade científica: “As Faculdades de Medicina representam o maior êxito do ensino superior brasileiro, no sentido de real incorporação da ciência experimental à formação profissional superior [...] nas escolas de medicina estaria o modelo para a implantação da universidade moderna no Brasil" 21 (p. 79).

"É pela Medicina que se introduz na cultura brasileira o espírito científico moderno, caracterizado pelo método experimental. Daí serem as escolas de Medicina, em oposição às de Direito e mesmo às de Engenharias, o verdadeiro núcleo do pensamento empírico-indutivo, que lentamente começa a emergir no quadro intelectual brasileiro" 23 (p. 106).

"A lição que nos dá a medicina nacional é a de que não são mudanças formais de estruturas que nos irão dar a ciência de que precisamos, mas mu- 
danças de mentalidade, de atitudes, aceitação do método científico, prática de experimentação no campo da ciência pura e aplicada e lúcida e saudável emulação profissional, fundada em altos padrões de competência e honestidade científica, de que as escolas de medicina brasileiras nos dão o exemplo" 23 (p. 166).

Para ajudar a compreender esse aparente descompasso, propomos uma hipótese, fundada em raízes filosóficas comuns e nas convergências pragmáticas entre o pensamento anisiano e a obra de Abraham Flexner (1866-1959), desencadeador da maior reforma na história da educação superior na America do Norte, na primeira metade do século XX 38 .

Abraham Flexner publica em 1910 um estudo sobre a educação médica norte-americana, cujo título - Relatório Flexner 39 - consagra o nome de seu autor, que termina por revolucionar o conceito de universidade em todo o mundo. O Relatório Flexner destaca um importante elemento que interessa à presente discussão: tratase da constatação de que as escolas médicas se constituíam como feudos soberanos dentro das universidades. Tais escolas (ou faculdades) apenas nominalmente se vinculavam às instituições universitárias e, quando assim ocorria, portavam-se como pequenas universidades separadas dentro das universidades, com peculiaridades e regras próprias. Uma das suas principais recomendações foi reintegrar a faculdade de medicina, e posteriormente todas as "escolas imperiais", à instituição universitária. Esse aspecto da obra flexneriana é pouco conhecido, para não dizer praticamente ignorado, entre nós, mesmo tendo constituído uma das principais bases da crítica anisiana à universidade brasileira, bonapartista e conimbricense 23 .

Entre 1915 e 1926, Flexner passa a orientar sua atividade reformadora para o ensino secundário, financiando programas de articulação entre universidades e escolas experimentais inspiradas na filosofia do pragmatismo. Algumas idéias precursoras das pedagogias ativas (reunidas num texto de Flexner intitulado A Modern School, publicado em 1916) 40 haviam sido incorporadas ao projeto da Lincoln School, pioneiro colégio de aplicação vinculado ao Teacher's College, onde Anísio estagiou. Em 1926, Flexner retorna à Oxford University, na Inglaterra, convidado a ministrar conferências que, depois reunidas em livro (Universities: American, English, German, publicado em 1930) ${ }^{41}$, trazem uma dura análise crítica dos principais modelos de universidade da época, completada com a prospecção do que seria a "universidade do futuro".

Durante seu mestrado nos Estados Unidos, entre 1928 e 1929, Anísio Teixeira toma contato com a obra de Abraham Flexner 8. Não há registros de que tenha ocorrido algum encontro pessoal entre o jovem e então desconhecido educador baiano e o já famoso e influente líder intelectual da reforma universitária estadunidense. Anísio Teixeira estuda na Universidade de Columbia quando Flexner já havia se aposentado do General Board of Education e se encontrava na Europa, explorando o cenário universitário europeu. Porém não há dúvidas de que, por um lado, ao explicitar a pedagogia operativa da Escola Parque de Salvador e da rede de escolas oficinas e, por outro lado, ao conceber a estrutura curricular aberta da "universidade brasileira do futuro", tanto na UDF quanto na UnB, Anísio tem conhecimento, pelo menos, dos principais textos flexnerianos.

Em vários de seus escritos, Anísio menciona Flexner com respeito e pertinência. Num desses momentos 21 , refere-se certamente às conferências de Oxford, sem no entanto utilizar a citação bibliográfica pertinente: "é necessário que o país se fixe na idéia, que também inspirou Abraham Flexner nos Estados Unidos, de criar a escola pósgraduada" 21 (p. 203). E mais adiante admite que, no Brasil, "persiste a tradição da escola superior independente e autosuficiente e da universidade como confederação de escolas, lembrando a de Londres - que Flexner dizia não ser universidade - em contraste com a universidade integrada do tipo anterior" 21 (p. 208).

Por outro lado, o referencial pedagógico anisiano é de muitas maneiras similar ao sistema de aprendizagem prática com que Flexner traduz o pragmatismo de William James (seu professor no doutorado na Harvard) e John Dewey (parceiro no movimento pela escola democrática). Ambos defendem modelos inovadores de ensino -aprendizagem, antecipando em décadas a pedagogia das competências, o uso de estratégias pedagógicas ativas para a educação superior, a aprendizagem baseada em estudos de casos para solução de problemas concretos, preconizando a formação de profissionais nos contextos da prática concreta, no que veio a se chamar de Problem-Based-Leaning (PBL) 42.

Em vários pontos cruciais no panorama atual do ensino médico, Flexner e Anísio revelam impressionante convergência de ideias. Neste aspecto específico, vejamos primeiro Flexner 39 (p. 53): “No lado pedagógico, a medicina moderna, como todo ensino científico, é caracterizada por atividade. O estudante não mais apenas observa, escuta e memoriza, ele faz. Suas próprias atividades no laboratório e na clínica são os principais fatores na sua instrução e na sua disciplina. Uma educação em medicina hoje envolve tanto o aprender quanto o aprender como [learning how]. $O$ estudante não pode efetivamente conhecer a 
menos que saiba como fazer [know how]" 39 (p. 53 , grifo no original).

E agora Anísio 21 (p. 189): "Está claro que se sabe que o aprender se fará mais eficiente se ensinarmos como se estivéssemos levando o aprendiz a descobrir. Também se sabe que ensinar hoje é ensinar a aprender. Sabe-se ainda que não se deve ensinar pela informação, mas levando o aluno a apreender a 'estrutura' do saber que estiver estudando".

Nenhuma surpresa em afirmações dessa natureza, ainda mais escritas por criadores de métodos notáveis de ação pedagógica, em distintos momentos da história, antecipando teorizações do pragmatismo em relação à utilidade da experiência, da vivência e da práxis como modelo educacional.

Mais interessante ainda é verificar que Abraham Flexner, e nisso Anísio também o segue, antecipa o conceito de "educação para toda a vida" (lifelong learning), hoje apresentado como grande novidade na proposição de metodologias ativas de ensino-aprendizagem. Nas palavras de Flexner 40 (p. 55): “O progresso da ciência e a prática científica ou inteligente da medicina emprega, portanto, exatamente a mesma técnica. Para usá-la, seja na pesquisa ou na prática, o estudante deve ser treinado no exercício positivo de suas faculdades; e se foi assim treinado, a escola médica inicia em vez de completa sua educação como médico. Ela [a escola médica] não pode, em nenhuma hipótese, transmitir ao estudante mais que uma fração dos tesouros reais da ciência, porém pode, pelo menos, colocá-lo no caminho de, consistentemente, ampliar seus conhecimentos".

Ao analisar criticamente a educação superior no Brasil nos anos 1930 e 1950, Anísio reitera Flexner que, no seu tempo, avaliou rigorosamente a educação médica no contexto da universidade norte-americana de 1910. Ambos denunciam a excessiva precocidade na escolha das carreiras; a submissão ao mercado de ensino, de trabalho e de serviços; a não integração entre graduação profissional e formação universitária; a ausência da formação científica, cultural e humanística prévia 34,35,36. Parece até que estão a avaliar o contexto universitário brasileiro deste início de século XXI 34. De fato, ainda hoje, o modelo curricular de ensino superior hegemônico no Brasil se mostra incompatível com os regimes curriculares das melhores universidades do mundo 36 .

Observamos, no contexto nacional, omissão ou ocultamento dos eixos principais do relatório reformador de Flexner - por um lado, a denúncia do isolamento das faculdades de medicina em relação à instituição universitária que a integra, o "império dentro do império", e por outro lado, a necessidade de uma estrutura curricular que priorize a formação geral em regime de ciclos. Conforme avaliamos em outra oportunidade 43 , tais pontos cegos indicam flagrante mecanismo de recalque no processo de produção de um discurso ideológico no plano do imaginário, defensivo do status quo político-institucional da educação médica brasileira.

O primeiro ponto dessa análise, tipicamente flexneriana, é reproduzido sem hesitação por Anísio, referindo-se às ambiguidades e contradições do ensino superior no Brasil: "Gozando do maior prestígio social, herdado da própria profissão médica e fortalecido pelo valor de seus professores, habitualmente profissionais de grande relevo, as escolas de Medicina guardaram o seu isolamento e auto-suficiência, existindo dentro da universidade, mas não pertencendo à universida$d e " 23$ (p. 118).

Dado que, nas universidades brasileiras - não podemos dizer em todas, dadas as exceções - as faculdade de medicina continuam, em pleno século XXI, impérios dentro do império, seria a invisibilidade do pensamento anisiano no campo da saúde no Brasil parte do mesmo movimento de recalque que distorce e perverte o conjunto de aportes advindos do pragmatismo crítico, dos quais Flexner se fez militante? Mais ainda, o duplo movimento de satanização de Flexner e negação de Anísio, sintoma revelador da estrutura elitizada, alienante e fragmentadora da educação superior brasileira, manifesta de modo mais agudo, profundo e crucial no ensino médico?

Reforçando o argumento que subsidia nossa hipótese, em distintos momentos de sua obra, Anísio enfatiza dois aspectos cruciais para a questão da educação superior no campo da Saúde: o caráter público da universidade e o papel central da autonomia na educação superior. Em relação ao primeiro ponto, Anísio é premonitório também na identificação dos problemas estruturais da universidade brasileira que levaram a um processo de expansão desenfreada, à base da grande ampliação do setor privado, incentivada pela política educacional dos anos 1990. Em sua vasta obra teórica e prática, encontram-se inúmeras referências e soluções criativas para diversas questões atuais e relevantes para renovação da universidade: exposição à diversidade cultural, reconhecimento da realidade socioeconômica iníqua e adversa, revisão de um contexto histórico doloroso, imersão em planos de práticas concretas, transgressão de papeis pedagógicos, transposição de fronteiras disciplinares, sem perder a competência científica, tecnológica e praxiológica.

No que concerne à questão da autonomia, lamenta o fato do mundo inteiro ter avançado numa certa direção (modelo Humboldtiano e 
Flexneriano) e a universidade brasileira ter conservado um sistema superado (o modelo lusobonapartista). Em suas palavras 21 (p. 182): “na universidade, sobretudo a alemã, que se fez modelo da universidade moderna, a idéia da liberdade de ensinar e liberdade de aprender foi consagrada como a sua lei maior. Não se compreendia ensino que não contasse com a plena participação do estudante. Essas liberdades de ensinar e de aprender tomam na universidade americana a forma de livre oferta de cursos pelo professor e livre escolha pelos alunos".

A questão da autonomia universitária permite ressaltar uma outra referência crítica ao campo da saúde na obra anisiana. Como a corporação médica se apresenta e se confirma como uma das mais poderosas na manutenção do status quo social e as faculdades de medicina representam os velhos regimes curriculares, Anísio não tarda a identificar a submissão às corporações profissionais como forte obstáculo à modernização na educação superior em geral e no ensino médico em especial 23.

"Logo, embora as escolas de Medicina sejam as mais sensíveis ao progresso científico da profissão médica, nem por isto elas se fazem instituições dinâmicas predispostas à mudança, mas afeiçoam-se aos padrões adquiridos e se fecham como fortalezas dentro de seus muros, que não são os da universidade, mas os da própria escola" 23 (p. 107).

Assim, não obstante apreciar o rigor científico que atribuía à escola médica do seu tempo, como vimos acima, Anísio Teixeira se posiciona fortemente contra o perfil profissionalizante e estreito das velhas faculdades, representativas de uma universidade conservadora, submetida ao jugo do corporativismo e ao poder das elites pós-coloniais.

\section{Comentários finais}

No presente artigo, trazemos uma apreciação da atualidade e pertinência do pensamento anisiano perante inovações pedagógicas e curriculares cada vez mais influentes no campo da Saúde em todo o mundo. Identificamos nesse vetor de inovação uma clara inspiração flexneriana, mesmo distanciada no tempo - e, no Brasil, pouco reconhecida e, muitas vezes, renegada. Propomos que Anísio Teixeira e Abraham Flexner compartilham um mesmo tronco conceitual, o pragmatismo deweyano, chave que explicaria a profunda convergência intelectual entre esses mestres da educação contemporânea. Essa análise subsidia uma hipótese que potencialmente permite compreender a ausência ou a invisibilidade das ideias anisianas no discurso institucional e nas propostas de formação universitária de trabalhadores no campo da saúde no Brasil.

Diferentemente de Flexner, a luta de Anísio Teixeira visando à implantação de inovações institucionais, curriculares e pedagógicas na educação superior brasileira pode ser considerada um enorme fracasso político. Mais ainda, restaurações conservadoras e reações políticas aos seus monumentais projetos de renovação da universidade foram desencadeadas, fomentadas e concentradas nas faculdades de medicina. A invisibilidade de Anísio no campo do ensino médico nos faz ver que, de fato, parafraseando Bruno Latour 44 , nunca fomos flexnerianos.

Vejamos rapidamente dois precedentes históricos que reforçam essa hipótese. Em 1936, dando vazão ao entusiasmo provocado pela primeira tentativa de universidade anisiana, a Universidade do Distrito Federal acima citada, Antonio da Silva Melo apresentou uma "proposta de reforma da mais prestigiosa faculdade de medicina do país, vinculada à Universidade do Brasil" 45 (p. 581). A reforma preconizada pelo inquieto clínico carioca, formado em 1914 na Universidade de Berlim, são em tudo compatíveis com o Relatório Flexner: marco conceitual de base científica, dedicação exclusiva de docentes, revisão de currículos, redução de vagas, metodologia pedagógica baseada na prática, turmas menores em laboratórios e clínicas. As propostas modernizantes do modelo de formação médica de herança franco-lusitana defendidas por Silva Melo, convergentes com o racionalismo científico germânico-estadunidense, encontraram apenas indiferença 45 , num momento em que Anísio Teixeira se via perseguido pela polícia política do Estado Novo e pela neo-inquisição pedagógica da Igreja Católica 8,25.

Três décadas depois, na UnB projetada por Anísio Teixeira e Darcy Ribeiro - esta sim a primeira universidade consolidada com uma estrutura curricular baseada em ciclos de formação - não havia escola médica separada e sim um Centro (depois Faculdade) de Ciências da Saúde, destinado à formação integrada de todas as profissões da saúde. O retrocesso do experimento institucional e pedagógico da UnB 31, duramente reprimido pelo regime militar por ser considerado altamente subversivo, como vimos acima, resultou no enfraquecimento dos centros de formação, iniciado pela criação em 1999 de uma Faculdade de Medicina separada, destinada exclusivamente à formação de médicos, retomando o modelo tradicional de fragmentação institucional da universidade brasileira.

Assim, é cada vez mais crucial a promoção da cultura universitária, da integralidade na educa- 
ção, da interdisciplinaridade e da formação interprofissional, com autonomia, criatividade e responsabilidade social e incluindo o papel das artes e das ciências na reflexão-ação emancipadora. Não porque Flexner e Anísio escreveram isso em 1910 e em 1930, respectivamente, mas porque não faz sentido alguém ingressar, por exemplo, no primeiro ano de um curso profissional e graduar-se cinco, seis anos depois sem ter tido acesso aos temas da arte, da cultura, da civilização, do pensamento científico, da crítica social, que a própria Universidade fomenta e elabora como produtos culturais. De fato, nas universidades públicas brasileiras ainda predominam cursos onde o ingressante recebe uma lista detalhada de matérias, a ser seguida obrigatoriamente, disciplinadamente, do primeiro ao quarto ou quinto ou sexto ano, de modo que no momento da entrada o estudante já sabe o que cursará no último semestre da sua formação, preso na "grade curricular" 34. Mas também porque é absurda, principalmente no campo da formação em saúde, a permanência de programas lineares de graduação diretamente profissionalizantes, de base conteudista e tecnicista, sem espaço para a multireferencialidade ou para uma efetiva integração interdisciplinar e interprofissional, e, além de tudo isso, dissociados da realidade de saúde.

Para superar esta situação, propomos recriar a universidade pública brasileira como uma universidade popular anisiana, fora dos lugares de isolamento e alienação, rompendo os limites do "império dentro do império". Para tanto, além de ampliação e abertura a segmentos sociais excluídos, é necessário introduzir as culturas artísticas e humanísticas junto ao necessário, mas não suficiente, campo das ciências no ambiente universitário, sem hierarquias nem hegemonias, por meio de arquiteturas curriculares e modelos pedagógicos baseados em autonomia e flexibilidade. Do ponto de vista pedagógico, o maior desafio será pensar o educando como sujeito histórico e contextualizado, que assumirá o rumo de sua autoconstrução e do seu processo como sujeito de aprendizagem, devidamente acompanhado por professores, tutores e por seus próprios pares. Nessa universidade renovada, o estudante fará escolhas informadas e, quando necessário, poderá modificar seu itinerário curricular sem sucumbir à rigidez de pautas de treinamento pré-fixadas e logo superadas por realidades cambiantes; será protagonista, ativo e consciente, dos processos de ensino-aprendizagem e não mero coadjuvante marginalizado de um sistema burocrático alienante. Este desafio não é pequeno: como ser efetivamente criativo e progressivamente autônomo, em vez de continuar a fazer mais do mesmo, repetindo velhos modelos e revestindo-os com novas roupagens sem, de fato, transformar estruturalmente os processos de formação.

Neste artigo, buscamos demonstrar que uma exploração direta dos escritos de Anísio Teixeira e Abraham Flexner permite constatar que desafios dessa ordem já estavam presentes e cumpriam função estruturante em suas respectivas obras. De fato, em ambos os autores encontramos permanente esforço de valorização de pedagogias ativas, fundadas na capacidade de aprender fazendo. Ademais, como ainda evidenciamos, inúmeros argumentos centrais do pensamento crítico de ambos enfatizam o papel das artes, das humanidades, das ciências e suas tecnologias como distintivo cultural da modernidade, tanto como elemento promotor da vida com equidade quanto como fator decisivo para a eficácia/ eficiência do processo permanente de ensinoaprendizagem.

Esperamos que este artigo possa contribuir para a construção de uma pauta nacional de inovação na Formação em Saúde realista institucionalmente, tecnologicamente competente, pedagogicamente eficiente, epistemologicamente consistente, socialmente justa e compatível com modelos contemporâneos internacionais. E que esse esforço de reflexão, aqui compartilhado, resulte em provocações, debates e discussões tão necessários neste momento em que constatamos um atraso centenário nos modelos de formação profissional à altura dos desafios da construção e consolidação de um sistema único de saúde em nosso país. 


\section{Resumen}

El objetivo del presente artículo es examinar elementos centrales del pensamiento-acción de Anísio Teixeira, con el fin de crear recursos que ayuden a la superación de la actual crisis de formación de personas en el ámbito de la salud. En primer lugar, se presenta un resumen de la biografía y obra de Anísio, evaluando su legado institucional e impacto en el escenario histórico de la educación brasileña. En segundo lugar, se discute el modelo anisiano de Universidad Popular, promovido e implantado en dos ocasiones durante la historia brasileña reciente, pese a que fue reprimido políticamente con dureza. En tercer lugar, se evalúa la contribución potencial de la obra anisiana en los de- bates político-pedagógicos actuales sobre formación profesional y académica en salud, centrándonos en las similitudes con modelos flexnerianos de renovación de la universidad. Por último, se propone la hipótesis de que la convergencia conceptual y pragmática entre Flexner y Anísio permite comprender la constatada ausencia o invisibilidad del pensamiento anisiano en la literatura académica sobre Educación en Salud, en el discurso institucional y en las prácticas de formación de trabajadores en salud en Brasil.

Educación en Salud; Universidades

\section{Referências}

1. Paim J, Travassos C, Almeida C, Bahia L, Macinko J. The Brazilian health system: history, advances, and challenges. Lancet 2011; 377:1778-97.

2. Rego S. Educação médica no Brasil no século XX. Boletim da ABEM 2000; XXVIII(2).

3. Batista KBC, Gonçalves OSJ. Formação dos profissionais de saúde para o SUS: significado e cuidado. Saúde Soc 2011; 20:884-99.

4. Almeida-Filho N. Higher education and health care in Brasil. Lancet 2011; 377:1898-900.

5. Temporão JG. Educação na saúde e saúde na educação. http://jornalggn.com.br/blog/luisnassif/ educacao-na-saude-e-saude-na-educacao-portemporao (acessado em 11/Dez/2013).

6. Rocha JA, organizador. Anísio em movimento. Brasília: Senado Federal; 2002.

7. Bortoloti KFS, Cunha MV. Anísio Teixeira e a psicologia: o diálogo com a psicanálise. História da Educação 2013; 17:59-77.

8. Viana-Filho L. Anísio Teixeira: a polêmica da educação. São Paulo: Editora UNESP/Salvador: EDUFBA; 2008.
9. Aguiar AC. Cultura de avaliação e transformação da educação médica: a ABEM na interlocução entre academia e governo. Rev Bras Educ Méd 2006; 30:98-101.

10. Amâncio Filho A, Vieira ALS, Garcia ACP. Oferta das graduações em Medicina e em Enfermagem no Brasil. Rev Bras Educ Méd 2006; 30:161-70.

11. Araujo ME. Educação superior em odontologia na perspectiva das políticas públicas de saúde [Tese de Livre Docência]. São Paulo: Faculdade de Odontologia, Universidade de São Paulo; 2004.

12. Saliba NA, Moimaz SA, Garbin CA, Diniz DG. Dentistry in Brazil: its history and current trends. J Dent Educ 2009; 73:225-31.

13. Feijó, EJ, Tavares CMM. Distance education in undergraduate nursing in the State of Rio de Janeiro: a sociocultural approach of structural markers - preview note. Online Braz J Nurs 2010; 9(1) http://www.objnursing.uff.br/index.php/nursing/ article/view/j.1676-4285.2010.2695. 
14. Del Ciampo LA, Del Ciampo IRL. Curso de medicina e ensino de pediatria nas escolas médicas brasileiras. Pediatria (São Paulo) 2010; 32:9-14.

15. Teixeira A. Ciência e arte de educar. Educação e Ciências Sociais 1957; 2:5-22.

16. Teixeira A. Mestres de amanhã. Revista Brasileira de Estudos Pedagógicos 1963; 40:10-9.

17. Teixeira A. A universidade de ontem e de hoje. Revista Brasileira de Estudos Pedagógicos 1964; 42:27-47.

18. Teixeira A. Uma perspectiva da educação superior no Brasil. Revista Brasileira de Estudos Pedagógicos 1968; 50:21-82.

19. Teixeira A. Cultura e tecnologia. Revista Brasileira de Estudos Pedagógicos 1971; 55:12-37.

20. Teixeira A. Educação no Brasil. Rio de Janeiro: Editora UFRJ; 1982.

21. Teixeira A. Ensino superior no Brasil: análise e interpretação de sua evolução até 1969. Rio de Janeiro: Editora UFRJ; 1989.

22. Teixeira A. Educação para a democracia: introdução à administração educacional. Rio de Janeiro: Editora UFRJ; 1997.

23. Teixeira A. Educação e universidade. Rio de Janeiro: Editora UFRJ; 1998

24. Teixeira A. Educação e o mundo moderno. Rio de Janeiro: Editora UFRJ; 2006.

25. Mendonça AW. Anísio Teixeira e a universidade de educação. Rio de Janeiro: Editora UERJ; 2002.

26. Ribeiro D. A invenção da Universidade de Brasília 1961-1995. Cartas: falas, reflexões, memórias. Brasília: Gabinete do Senador Darcy Ribeiro, Senado Federal; 1995.

27. Salmeron R. A universidade interrompida: Brasília, 1964-1965. Brasília: Editora UnB; 2008.

28. José E. O assassinato de Anísio Teixeira. Carta Capital. http://www.cartacapital.com.br/socie dade/o-assassinato-de-anisio-teixeira-2603.html (acessado em 10/Jul/2014).

29. Sousa-Santos B. Pela mão de Alice: o social e o político na transição pós-moderna. São Paulo: Cortez Editora; 1997.

30. Portugal C. Outras cores: 27 artistas da Bahia - reportagens plásticas. Salvador: Fundação Casa de Jorge Amado; 1994.

31. Plano Orientador da Universidade de Brasília. Brasília: Editora UnB; 1962.
32. Pimenta A. Universidade. A destruição de uma experiência democrática. Petrópolis: Editora Vozes; 1984.

33. Castilho F. O conceito de universidade no projeto da UNICAMP. Campinas: Editora da Unicamp; 2008.

34. Almeida-Filho N. Universidade nova: textos críticos e esperançosos. Brasília: Editora UnB/Salvador: EDUFBA; 2007.

35. Sousa-Santos B, Almeida-Filho N. A universidade no século XXI: para uma universidade nova. Coimbra: Almedina; 2008.

36. Seabra-Santos F, Almeida-Filho N. A quarta missão da universidade. Coimbra: EduCoimbra/Brasília: Editora UnB; 2012.

37. Brasil. Lei de Diretrizes e Bases da Educação Nacional. Lei no 9.394, de 20 de dezembro de 1996. http://portal.mec.gov.br/arquivos/pdf/ldb.pdf (acessado em 10/Jul/2014).

38. Ludmerer K. Understanding the Flexner Report. Acad Med 2010; 85:193-6.

39. Flexner A. Medical education in the United States and Canada. New York: Carnegie Foundation for the Advancement of Science; 1910. http://www. carnegiefoundation.org/files/elibrary (acessado em $02 / J u n / 2014$ )

40. Flexner A. A modern college and a modern school. New York: Doubleday, Page and Co.; 1923.

41. Flexner A. Universities: American, English, German. London/Oxford/New York: Oxford University Press; 1968.

42. Brears L, MacIntyre B, O'Sullivan G. Preparing teachers for the 21st century: using PBL as an integrating strategy in science and technology education. Design \& Technology Education 2011; 16: 36-46.

43. Almeida Filho N. Reconhecer Flexner: inquérito sobre produção de mitos na educação médica no Brasil contemporâneo. Cad Saúde Pública 2010; 26:2234-49.

44. Latour B. Jamais fomos modernos: ensaio de antropologia simétrica. Rio de Janeiro: Editora 34; 1994.

45. Kemp A, Edler F. A reforma médica no Brasil e nos Estados Unidos: uma comparação entre duas retóricas. Hist Ciênc Saúde-Manguinhos 2004; 11: 569-85.

Recebido em 20/Jul/2014

Aprovado em 28/Jul/2014 